\title{
ESTIMATIVAS DE HERDABILIDADE E CORRELAÇÕES QUANTO À PRODUÇÃO DE GRÃOS E OUTRAS CARACTERÍSTICAS AGRONÔMICAS EM POPULAÇÕES DE TRIGO'
}

\author{
CARLOS EDUARDO DE OLIVEIRA CAMARGO², ANTONIO WILSON PENTEADO FERREIRA FILHO ${ }^{2}$ \\ e JOÃO CARLOS FELICIO ${ }^{3}$
}

RESUMO - Objetivou-se estimar os valores da variância, da heterose e heterobeltiose, e da herdabilidade em sentido restrito quanto a altura da planta de trigo (Triticum aestivum L.), comprimento da espiga, comprimento do internódio da raque e produção de grãos, e quanto às correlações de ambiente, fenotípicas e genéticas, entre essas características. Foram também estimados os graus de dominância em relação a todas as características, com exceção da produção de grãos. O experimento foi instalado em telado, no Núcleo Experimental de Campinas, empregando cruzamentos entre a cultivar IAC-227 ( $\left.\mathrm{P}_{1}\right)$, de porte alto, e quatro linhagens mexicanas, de porte baixo: $\mathrm{CMH}$ 78.390/ CMH 77A. 917// CMH 79.215 ( $\left.\mathrm{P}_{2}\right)$, CMH 79.959/2* CNO $79\left(\mathrm{P}_{3}\right)$, CMH 79.481/ CMH 77A. $917\left(\mathrm{P}_{4}\right)$ e CMH 80A. $747\left(\mathrm{P}_{5}\right)$. Os valores da herdabilidade em sentido restrito, referente a altura da planta $(0,608-0,861)$, comprimento da espiga $(0,406-0,667)$, comprimento do internódio da raque $(0,545-0,781)$ e produção de grãos $(0,421-0,550)$ indicaram que grande parte da variabilidade genética verificada nas populações híbridas quanto a essas características foi causada por genes com ação aditiva. As correlações fenotípicas entre altura da planta e produção de grãos e entre comprimento da espiga e comprimento do internódio da raque foram positivas e significativas em todos os cruzamentos considerados, o que mostra haver associação entre esses caracteres; portanto, os resultados obtidos sugerem que o estudo de grandes populações $\mathrm{F}_{2}$ seria de interesse para assegurar maior freqüência de recombinantes desejáveis, originando plantas semi-anãs com elevado potencial produtivo.

Termos para indexação: Triticum aestivum, comprimento da espiga, internódio da raque, heterose, heterobeltiose, graus de dominância.

\section{VARIANCE, HERITABILITY AND CORRELATIONS IN WHEAT HYBRID POPULATIONS FOR GRAIN YIELD AND OTHER AGRONOMIC CHARACTERISTICS}

\begin{abstract}
The objective of the present work was to estimate the variance, heterosis and heterobeltiosis, and the narrow-sense heritability values for grain yield, spike length, rachis internode length and height of wheat plants (Triticum aestivum L.), as well as the environmental, phenotypic and genetic correlations between these characteristics. Degrees of dominance were also estimated for all characteristics except for grain yield. The experiment was carried out at the Experimental Center, in Campinas, São Paulo State, Brazil, under a screen house condition on crosses of the standard height cultivar IAC-227 $\left(\mathrm{P}_{1}\right)$ with four mexican lines: CMH 78.390/ CMH 77 A.917// CMH $79.215\left(\mathrm{P}_{2}\right)$, CMH 79.959/2* CNO $79\left(\mathrm{P}_{3}\right), \mathrm{CMH} 79.481 / \mathrm{CMH}$ 77A.917 $\left(\mathrm{P}_{4}\right)$ and $\mathrm{CMH} 80 \mathrm{~A} .747\left(\mathrm{P}_{5}\right)$. The narrow sense heritability values for plant height $(0.608-0.861)$, spike length $(0.406-0.667)$, rachis internode length (0.545-0.781) and grain yield (0.421-0.550) indicated that the great part of the verified genetic variability in the hybrid populations for these traits were due to additive gene action. The phenotypic correlations between plant height with grain yield and between spike length and rachis internode length were positive and significant to all crosses, showing to have associations between these characters; however the obtained results suggest that large $F_{2}$ populations will be required to ensure the frequency of desired recombinants, showing semidwarf plants with high yield potential.

Index terms: Triticum aestivum, spike length, rachis internode heterosis, heterobeltiose, degree of dominance.

${ }^{1}$ Aceito para publicação em 30 de abril de 1999.

Parcialmente financiado pelas Cooperativas de Produtores Rurais do Vale do Paranapanema, Estado de São Paulo.

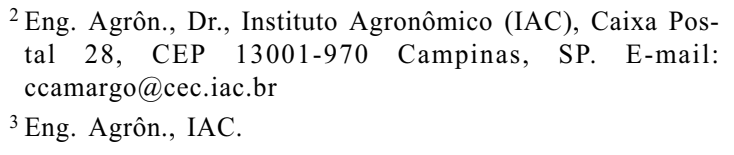




\section{INTRODUÇÃO}

Com a introdução da triticultura no cerrado e com a irrigação por aspersão, além da tolerância ao Al, as cultivares de trigo necessitam apresentar porte semianão, pois nessas condições a adubação nitrogenada é utilizada visando ao aumento da produção de grãos, e as cultivares de porte alto tornam-se passíveis de acamamento (Camargo et al., 1985).

Além do porte baixo, os trigos semi-anões mexicanos são portadores de palha forte, espigas longas e densas, e precocidade, entre outras características.

Os graus de dominância calculados em relação à altura das plantas em cruzamentos de quatro trigos de porte semi-anão com uma cultivar de porte alto mostraram que os genes de porte baixo das cultivares Siete Cerros, Vican-71 e Olesen tiveram um comportamento parcialmente recessivo, porém os genes da Tordo exibiram dominância parcial para porte baixo, sendo esta cultivar a melhor fonte, pela maior frequência de indivíduos de porte baixo nas populações avaliadas (Camargo \& Oliveira, 1981).

Os valores de heterose e heterobeltiose, calculados com relação à produção de grãos, mostraram que o cruzamento entre a 'IAC-5' (porte alto) e a 'Vican-71' (porte semi-anão) apresentou grande potencial de produção, sugerindo ter esse híbrido alta capacidade específica de combinação (Camargo \& Oliveira, 1981).

Altos valores da herdabilidade em sentido restrito para o caráter altura da planta de trigo foram calculados por Kronstad \& Foote (1964), Johnson et al. (1966), Ketata et al. (1976), Camargo et al. (1980), Camargo et al. (1992) e Ferreira Filho (1996). Altas estimativas da herdabilidade em sentido restrito para comprimento da espiga foram obtidas por Kronstad \& Foote (1964), Johnson et al. (1966) e Camargo (1984). Considerando o comprimento do internódio da raque, Ferreira Filho (1996) calculou médios a altos valores para a herdabilidade em sentido restrito. Estes resultados mostram a existência de efeitos aditivos na expressão genética desses caracteres, sugerindo que a seleção visando a esses caracteres seria efetiva nas primeiras gerações segregantes de um cruzamento.
A herdabilidade em sentido restrito para produção de grãos tem sido estimada com valores médios a baixos (Fonseca \& Patterson, 1968; Camargo et al., 1992), sugerindo que a seleção para esse caráter seria efetiva nas últimas gerações segregantes, onde o valor genético da progênie seria mais precisamente determinado.

O estudo das associações entre as características de uma população híbrida permite saber se eles são geneticamente dependentes ou independentes, isto é, se tendem ou não a permanecer associados nas progênies durante os sucessivos ciclos de seleção (Johnson et al., 1966; Fonseca \& Patterson, 1968).

Correlações fenotípicas positivas e altamente significativas foram obtidas com relação à produção de grãos com altura da planta, comprimento da espiga e do internódio da raque em cruzamentos envolvendo a cultivar IAC-5, de porte alto, e quatro diferentes fontes genéticas de nanismo (Camargo \& Oliveira, 1983).

Este trabalho teve por objetivo estimar os valores da variância, da heterose e da heterobeltiose, e da herdabilidade em sentido restrito e as associações entre produção de grãos, comprimento da espiga, altura da planta e comprimento do internódio da raque, em populações híbridas de trigo. Objetivou-se também estimar os graus de dominância para as características já mencionadas com exceção da produção de grãos.

\section{MATERIAL E MÉTODOS}

Foram realizados cruzamentos entre a cultivar IAC-227 $\left(\mathrm{P}_{1}\right)$, de origem nacional, de porte alto, com comprimento intermediário da espiga e do internódio da raque e adaptada ao cultivo em condição de sequeiro, e as linhagens mexicanas de porte baixo e com alto potencial produtivo em condição de irrigação: CMH 78.390/ CMH 77A.917// CMH 79.215 ( $\left.\mathrm{P}_{2}\right), \mathrm{CMH} 79.959 / 2 * \mathrm{CNO} 79\left(\mathrm{P}_{3}\right)$, $\begin{array}{lllll}\mathrm{CMH} & 79.481 / \quad \mathrm{CMH} & 77 \mathrm{~A} .917 & \left(\mathrm{P}_{4}\right) & \mathrm{e}\end{array}$ CMH 80 A.747 $\left(\mathrm{P}_{5}\right)$. O $\mathrm{P}_{2}, \mathrm{P}_{3}$ e $\mathrm{P}_{5}$ apresentaram espigas compridas, com médio a grande comprimento do internódio da raque, e o $\mathrm{P}_{4}$, espigas curtas e densas.

Além dos genitores, integraram o ensaio as gerações $F_{1}$ e $\mathrm{F}_{2}$ dos cruzamentos entre IAC-227 x CMH 78.390/CMH 77A.917// CMH 79.215 $\left(\mathrm{P}_{1} \mathrm{xP}_{2}\right)$; IAC-227 x CMH 79.959/2* CNO $79\left(\mathrm{P}_{1} \times \mathrm{P}_{3}\right) ; \quad \mathrm{IAC}-227 \times \mathrm{CMH} 79.481 /$ 
CMH 77A. $917\left(\mathrm{P}_{1} \mathrm{xP}_{4}\right)$ e IAC-227 x CMH 80A.747 $\left(\mathrm{P}_{1} \mathrm{xP}_{5}\right)$ e as populações $\mathrm{F}_{1}$, dos retrocruzamentos para ambos os parentais a saber: $\left(\mathrm{P}_{1} \times \mathrm{P}_{2}\right) \mathrm{xP}_{1} ;\left(\mathrm{P}_{1} \mathrm{xP}_{2}\right) \mathrm{xP}_{2}$; $\left(\mathrm{P}_{1} \times \mathrm{P}_{3}\right) \mathrm{xP}_{1} ;\left(\mathrm{P}_{1} \mathrm{xP}_{3}\right) \mathrm{x}_{3} ;\left(\mathrm{P}_{1} \mathrm{xP}_{4}\right) \mathrm{xP}_{1} ; \quad\left(\mathrm{P}_{1} \mathrm{xP}_{4}\right) \mathrm{xP}_{4}$; $\left(\mathrm{P}_{1} \mathrm{xP}_{5}\right) \mathrm{xP}_{1} \mathrm{e}\left(\mathrm{P}_{1} \mathrm{xP}_{5}\right) \mathrm{xP}_{5}$.

No ensaio, instalado em 1992 em telado contra o ataque de pássaros, localizado no núcleo experimental de Campinas, do Instituto Agronômico, utilizou-se o delineamento experimental de blocos ao acaso, com 21 tratamentos, os quais incluem os cinco parentais, os $4 \mathrm{~F}_{1} \mathrm{~s}$, os

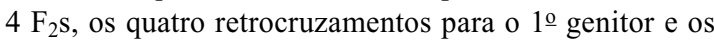
4 retrocruzamentos para o 2 o genitor, com quatro repetições. Cada repetição foi constituída de quatro vasos com três plantas para os pais e $\mathrm{F}_{1} \mathrm{~s}$, por 20 vasos para os $\mathrm{F}_{2} \mathrm{~S}$ e por 12 vasos para os retrocruzamentos. $\mathrm{O}$ conjunto das quatro repetições foi constituído de 848 vasos de plástico preto de aproximadamente $25 \mathrm{~cm}$ de altura e $20 \mathrm{~cm}$ de diâmetro os quais foram preenchidos com solo adubado sem Al trocável. Os vasos foram distribuídos distante um do outro na linha de $10 \mathrm{~cm}$ e entre linhas de $40 \mathrm{~cm}$. Foi colocada uma linha adicional de vasos semeados com a cultivar IAC-24 contornando o experimento, visando minimizar os efeitos de bordadura.

Os dados, coletados individualmente para cada planta, basearam-se nos caracteres seguintes:

Altura das plantas - medida, em centímetros, da superfície do solo até a ponta da espiga do colmo mais alto, excluindo as aristas;

Comprimento da espiga - medida, em centímetros, do ponto de inserção da primeira espigueta basal até a ponta da espiga do colmo principal, excluindo as aristas;

Comprimento do internódio da raque - calculado pela relação entre o comprimento, em centímetros, da espiga do colmo principal, excluindo as aristas e o número de espiguetas da espiga do colmo principal;

Produção de grãos - peso, em gramas, da produção total de grãos de cada planta.

Todos os caracteres estudados foram submetidos à análise da variância, sendo o teste $\mathrm{F}$ utilizado para determinar efeitos significativos. $\mathrm{O}$ valor de cada parcela utilizado na análise de variância foi considerado como a média das plantas de cada genótipo na repetição. Os efeitos de geração na análise de variância foram divididos em componentes, para detectar diferenças dentro de e entre gerações.

Calcularam-se os graus de dominância quanto a altura das plantas, comprimento da espiga e comprimento do internódio da raque, com base nos componentes da variância, para cada cruzamento, segundo o método proposto por Mather \& Jinks (1977).

A heterose foi calculada para altura das plantas, comprimento da espiga, comprimento do internódio da raque e produção de grãos, como a porcentagem de aumento do $F_{1}$ ou $F_{2}$ sobre a média dos parentais, mediante a fórmula descrita por Matzinger et al. (1962). A superioridade do $F_{1}$ ou $F_{2}$ sobre a média do genitor que apresentou o dado mais elevado com referência ao caráter avaliado foi definida como heterobeltiose e estimada usando-se a fórmula proposta por Fonseca \& Patterson (1968).

A estimativa da herdabilidade em sentido restrito- $\mathrm{h}^{2}{ }_{\mathrm{ns}}$ (proporção entre a variância genética aditiva e a variância fenotípica) foi calculada para os quatro caracteres em estudo, para cada cruzamento pelo método de Warner (1952), utilizando-se dados de plantas individuais. O erro-padrão para a $\mathrm{h}^{2}$ ns foi obtido conforme método de Ketata et al. (1976).

As correlações fenotípicas, genotípicas e ambientais foram usadas para estimar o grau de associação entre os quatro caracteres em estudo para cada população, mediante dados de plantas individuais. Como sugerido por Falconer (1960), as correlações usando dados de $F_{1}$ foram consideradas ambientais e aquelas com dados de $\mathrm{F}_{2}$, fenotípicas. As correlações genotípicas foram calculadas pela seguinte fórmula:

$r_{G}=\left(r_{F}-e_{X} e_{Y} r_{A}\right) / h_{X} h_{Y}$

onde:

$\mathrm{r}_{\mathrm{G}}=$ correlação genotípica entre os caracteres $\mathrm{x}$ e y; $\mathrm{r}_{\mathrm{F}}=$ correlação fenotípica entre $\mathrm{x}$ e $\mathrm{y} ; \mathrm{r}_{\mathrm{A}}=$ correlação ambiental entre x e y; $h_{X}$ e $h_{Y}=$ raiz quadrada da herdabilidade em sentido restrito para os caracteres $\mathrm{x}$ e $\mathrm{y}$ respectivamente, considerando separadamente cada cruzamento; $e_{X}=\sqrt{1-h^{2}{ }_{X}}$ e $e_{Y}=\sqrt{1-h^{2}{ }_{Y}}$

\section{RESULTADOS E DISCUSSÃO}

As análises de variância referentes a altura da planta, comprimento da espiga, comprimento do internódio da raque e produção de grãos dos genótipos de trigo estudados, encontram-se na Tabela 1. As médias de cada genótipo referentes a cada um dos caracteres em estudo estão contidas na Tabela 2.

Empregando-se o teste de Tukey a 5\%, para a comparação entre a altura da planta dos diferentes genótipos utilizados como genitores, verificou-se que a cultivar IAC-227 $\left(\mathrm{P}_{1}\right)$ apresentou a maior média, diferindo significativamente das quatro linhagens mexicanas. $\mathrm{P}_{3}$ foi o mais alto entre os genótipos mexicanos em estudo, diferindo estatisticamente dos demais. $\mathrm{P}_{4}$ e $\mathrm{P}_{5}$ foram os mais baixos, diferindo de todos os pais estudados, porém não diferiram entre 
si. Comparando-se as médias dentro das populações $\mathrm{F}_{1}$, vê-se que o cruzamento $\mathrm{P}_{1} \mathrm{xP}_{3}$ apresentou plantas mais altas, diferindo dos demais cruzamentos, que, por sua vez, não diferiram entre si. Em relação às médias das populações $\mathrm{F}_{2}, \mathrm{P}_{1} \mathrm{xP}_{3}$ e $\mathrm{P}_{1} \times \mathrm{XP}_{5}$ mostraram as plantas mais altas e mais baixas, respectivamente, diferindo entre si e dos cruzamentos $\mathrm{P}_{1} \times \mathrm{P}_{2}$ e $\mathrm{P}_{1} \mathrm{xP}_{4}$, que por sua vez não apresentaram diferenças significativas entre si. Pelas médias dos retrocruzamemtos para o $1^{\underline{0}}$ genitor, o genótipo $\left(\mathrm{P}_{1} \mathrm{xP}_{3}\right) \mathrm{xP}_{1}$ exibiu as plantas mais altas, diferindo dos demais, que não diferiram entre si. Em relação aos

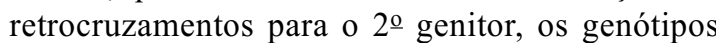
$\left(\mathrm{P}_{1} \mathrm{xP}_{3}\right) \mathrm{xP}_{3} \mathrm{e}\left(\mathrm{P}_{1} \mathrm{xP}_{5}\right) \mathrm{xP}_{5}$ apresentaram as plantas mais altas e mais baixas, respectivamente, diferindo entre si e dos demais, que, por sua vez, não diferiram entre si. As linhagens CMH 78.390/CMH 77A.917//CMH $79.215\left(\mathrm{P}_{2}\right), \mathrm{CMH} 79.481 / \mathrm{CMH} 77 \mathrm{~A} .917\left(\mathrm{P}_{4}\right)$ e
CMH 80A.747 $\left(\mathrm{P}_{5}\right)$ apresentaram grande potencial em transferir para suas progênies a característica porte baixo, confirmando resultados de trabalho de Ferreira Filho (1996) empregando a segunda linhagem em cruzamentos com a cultivar BH-1146, de porte alto.

Considerando o comprimento da espiga, verificou-se, através das médias dos genitores, grande variabilidade genética, revelando que o maior comprimento da espiga foi do $\mathrm{P}_{5}$ e o menor do $\mathrm{P}_{4}$, diferindo ambos estatisticamente dos demais. A população $\mathrm{F}_{1}$ do híbrido $\mathrm{P}_{1} \mathrm{xP}_{4}$ produziu as espigas mais curtas, diferindo estatisticamente dos demais, que, por sua vez, não diferiram entre si. As espigas do híbrido $\mathrm{P}_{1} \mathrm{xP}_{5}$, em geração $\mathrm{F}_{2}$, foram as mais compridas, diferindo estatisticamente dos demais. As populações dos retrocruzamentos $\left(\mathrm{P}_{1} \mathrm{xP}_{2}\right) \mathrm{xP}_{1}$, $\left(\mathrm{P}_{1} \mathrm{XP}_{3}\right) \mathrm{xP}_{1} \mathrm{e}\left(\mathrm{P}_{1} \mathrm{xP}_{5}\right) \mathrm{xP}_{1}$ apresentaram espigas signifi-

TABELA1. Resultados da análise de variância para altura da planta, comprimento da espiga, comprimento do internódio da raque e produção de grãos de diferentes genótipos de trigo estudados em ensaio instalado no Centro Experimental de Campinas, SP, em 1992.

\begin{tabular}{|c|c|c|c|c|c|}
\hline Causas de variação & G.L. & $\begin{array}{l}\text { Altura } \\
\text { da } \\
\text { planta } \\
(\mathrm{cm})\end{array}$ & $\begin{array}{l}\text { Compri- } \\
\text { mento da } \\
\text { espiga } \\
(\mathrm{cm})\end{array}$ & $\begin{array}{l}\text { Compr. do } \\
\text { internódio da } \\
\text { raque } \\
(\mathrm{mm})\end{array}$ & $\begin{array}{l}\text { Produção } \\
\text { de } \\
\text { grãos } \\
\text { (g) }\end{array}$ \\
\hline Repetições & 3 & 1,07 & 0,25 & $0,0012 *$ & $12,26^{* *}$ \\
\hline Genótipos & 20 & $736,64 * *$ & $23,48 * *$ & $0,0450 * *$ & $80,69^{* *}$ \\
\hline Entre gerações & 4 & $1474,75^{* *}$ & $15,45^{* *}$ & $0,0252 * *$ & $200,63 * *$ \\
\hline Dentro de gerações & 16 & $552,12 * *$ & $25,49 * *$ & $0,0499 * *$ & $50,71 * *$ \\
\hline Genitores & 4 & $1360,77 * *$ & $61,35^{* *}$ & $0,1354 * *$ & $112,34 * *$ \\
\hline $\mathrm{F}_{1} \mathrm{~s}$ & 3 & $348,35^{* *}$ & $6,86^{* *}$ & $0,0119 * *$ & $60,13^{* *}$ \\
\hline $\mathrm{F}_{2} \mathrm{~s}$ & 3 & $218,29 * *$ & $13,41 * *$ & $0,0202 * *$ & $21,46 * *$ \\
\hline Retrocruzamentos para o $1^{\circ}$ genitor & 3 & $44,92 * *$ & $2,04 * *$ & $0,0036 * *$ & $9,17 *$ \\
\hline Retrocruzamentos para o $2^{\circ}$ genitor & 3 & $518,72 * *$ & $31,83 * *$ & $0,0499 * *$ & $29,88 * *$ \\
\hline Genitores $\mathrm{x}$ repetições & 12 & 4,20 & 0,12 & 0,0004 & 0,99 \\
\hline $\mathrm{F}_{1} \mathrm{~s} \times$ repetições & 9 & 8,90 & 0,24 & 0,0003 & 5,13 \\
\hline $\mathrm{F}_{2} \mathrm{~s} \times$ repetições & 9 & 3,23 & 0,05 & 0,0002 & 0,52 \\
\hline Retrocruz. para o $1^{0}$ genitor $\mathrm{x}$ rep. & 9 & 5,82 & 0,06 & 0,0001 & 1,99 \\
\hline Retrocruz. para o $2^{0}$ genitor $\mathrm{x}$ rep. & 9 & 5,19 & 0,31 & 0,0007 & 3,89 \\
\hline Entre Gerações x repetições & 12 & 6,75 & 0,05 & 0,0002 & 1,26 \\
\hline Dentro de Gerações x repetições & 48 & 5,39 & 0,15 & 0,0003 & 2,41 \\
\hline Genótipos $\mathrm{x}$ repetições & 60 & 5,66 & 0,13 & 0,0003 & 2,18 \\
\hline Total & 83 & & & & \\
\hline $\mathrm{CV} \%$ & & 3,02 & 3,69 & 3,55 & 9,35 \\
\hline
\end{tabular}


TABELA 2. Médias e diferenças mínimas significativas (d.m.s.) de altura da planta, comprimento da espiga, comprimento do internódio da raque e produção de grãos dos 21 genótipos de trigo, no Centro Experimental de Campinas, SP, em 1992.

\begin{tabular}{|c|c|c|c|c|}
\hline Genótipo & $\begin{array}{l}\text { Altura } \\
\text { da } \\
\text { planta } \\
(\mathrm{cm})\end{array}$ & $\begin{array}{l}\text { Compri- } \\
\text { mento da } \\
\text { espiga } \\
(\mathrm{cm})\end{array}$ & $\begin{array}{c}\text { Compr. do } \\
\text { internódio } \\
\text { da raque } \\
(\mathrm{cm})\end{array}$ & $\begin{array}{l}\text { Produção } \\
\text { de } \\
\text { grãos } \\
\text { (g) }\end{array}$ \\
\hline IAC-227 $\left(\mathrm{P}_{1}\right)$ & $95,2 \mathrm{a}$ & $7,7 \mathrm{c}$ & $0,43 b$ & $17,8 \mathrm{a}$ \\
\hline CMH 78.390/CMH 77A.917// CMH $79.215\left(\mathrm{P}_{2}\right)$ & $63,4 \mathrm{c}$ & $12,5 \mathrm{~b}$ & 0,49 & $16,6 \mathrm{a}$ \\
\hline CMH $79.959 / 2 *$ CNO $79\left(\mathrm{P}_{3}\right)$ & $76,4 b$ & $13,0 \mathrm{~b}$ & $0,71 \mathrm{a}$ & $8,3 b$ \\
\hline CMH 79.481/CMH 77A.917 $\left(\mathrm{P}_{4}\right)$ & $51,4 \mathrm{~d}$ & $5,3 \mathrm{~d}$ & $0,29 \mathrm{c}$ & $6,1 \mathrm{c}$ \\
\hline CMH 80A.747 $\left(\mathrm{P}_{5}\right)$ & $52,0 \mathrm{~d}$ & $14,6 \mathrm{a}$ & $0,72 \mathrm{a}$ & $8,9 b$ \\
\hline d.m.s. (Tukey a $5 \%$ ) & 4,6 & 0,8 & 0,05 & 2,2 \\
\hline $\mathrm{P}_{1} \times \mathrm{P}_{2}\left(\mathrm{~F}_{1}\right)$ & $84,9 b$ & $9,2 \mathrm{a}$ & $0,44 b$ & $18,4 \mathrm{ab}$ \\
\hline $\mathrm{P}_{1} \times \mathrm{P}_{3}\left(\mathrm{~F}_{1}\right)$ & $99,5 \mathrm{a}$ & $9,8 \mathrm{a}$ & $0,50 \mathrm{a}$ & $23,4 \mathrm{a}$ \\
\hline $\mathrm{P}_{1} \times \mathrm{P}_{4}\left(\mathrm{~F}_{1}\right)$ & $81,3 \mathrm{~b}$ & $7,1 \mathrm{~b}$ & $0,39 \mathrm{c}$ & $14,2 b$ \\
\hline $\mathrm{P}_{1} \times \mathrm{P}_{5}\left(\mathrm{~F}_{1}\right)$ & $78,5 \mathrm{~b}$ & $10,0 \mathrm{a}$ & $0,51 \mathrm{a}$ & $20,5 \mathrm{a}$ \\
\hline d.m.s. (Tukey a 5\%) & 6,6 & 1,1 & 0,04 & 5,0 \\
\hline$\overline{P_{1} \times P_{2}\left(F_{2}\right)}$ & $80,0 \mathrm{~b}$ & $10,0 \mathrm{c}$ & $0,47 b$ & $19,3 \mathrm{a}$ \\
\hline $\mathrm{P}_{1} \times \mathrm{P}_{3}\left(\mathrm{~F}_{2}\right)$ & $92,5 \mathrm{a}$ & $10,7 \mathrm{~b}$ & $0,54 \mathrm{a}$ & $18,0 \mathrm{a}$ \\
\hline $\mathrm{P}_{1} \times \mathrm{P}_{4}\left(\mathrm{~F}_{2}\right)$ & $79,5 b$ & $7,3 \mathrm{~d}$ & $0,40 \mathrm{c}$ & $14,0 \mathrm{c}$ \\
\hline $\mathrm{P}_{1} \times \mathrm{P}_{5}\left(\mathrm{~F}_{2}\right)$ & $75,4 \mathrm{c}$ & $11,5 \mathrm{a}$ & $0,56 \mathrm{a}$ & $16,3 b$ \\
\hline d.m.s. (Tukey a $5 \%$ ) & 4,0 & 0,5 & 0,03 & 1,6 \\
\hline$\left(\mathrm{P}_{1} \times \mathrm{P}_{2}\right) \times \mathrm{P}_{1}$ & $86,8 b$ & $8,8 \mathrm{~b}$ & $0,44 b$ & $18,2 \mathrm{ab}$ \\
\hline$\left(\mathrm{P}_{1} \times \mathrm{P}_{3}\right) \times \mathrm{P}_{1}$ & $94,1 \mathrm{a}$ & $9,2 \mathrm{ab}$ & $0,46 \mathrm{a}$ & $18,9 \mathrm{ab}$ \\
\hline$\left(\mathrm{P}_{1} \times \mathrm{P}_{4}\right) \times \mathrm{P}_{1}$ & $87,4 \mathrm{~b}$ & $7,8 \mathrm{c}$ & $0,41 \mathrm{c}$ & $17,7 \mathrm{~b}$ \\
\hline$\left(\mathrm{P}_{1} \times \mathrm{P}_{5}\right) \times \mathrm{P}_{1}$ & $88,4 \mathrm{~b}$ & $9,3 \mathrm{a}$ & $0,47 \mathrm{a}$ & $21,1 \mathrm{a}$ \\
\hline d.m.s. (Tukey a 5\%) & 5,3 & 0,5 & 0,02 & 3,1 \\
\hline$\left(P_{1} \times P_{2}\right) \times P_{2}$ & $71,7 b$ & $11,1 b c$ & $0,49 b$ & $16,1 \mathrm{a}$ \\
\hline$\left(\mathrm{P}_{1} \times \mathrm{P}_{3}\right) \times \mathrm{P}_{3}$ & $86,4 a$ & $12,0 \mathrm{~b}$ & $0,59 \mathrm{a}$ & $15,6 \mathrm{ab}$ \\
\hline$\left(\mathrm{P}_{1} \times \mathrm{P}_{4}\right) \times \mathrm{P}_{4}$ & $71,8 b$ & $7,1 \mathrm{~d}$ & $0,39 \mathrm{c}$ & $10,9 \mathrm{c}$ \\
\hline$\left(\mathrm{P}_{1} \times \mathrm{P}_{5}\right) \times \mathrm{P}_{5}$ & $58,5 \mathrm{c}$ & $13,8 \mathrm{a}$ & $0,64 \mathrm{a}$ & $11,4 b c$ \\
\hline d.m.s. (Tukey a $5 \%$ ) & 5,0 & 1,2 & 0,06 & 4,4 \\
\hline
\end{tabular}

cativamente mais compridas em relação ao $\left(\mathrm{P}_{1} \mathrm{xP}_{4}\right) \mathrm{xP}_{1}$, que exibiu as espigas mais curtas. Em relação aos retrocruzamentos para o $2 \underline{0}$ genitor, $\mathrm{O}$ genótipo $\left(\mathrm{P}_{1} \mathrm{xP}_{5}\right) \mathrm{xP}_{5}$ mostrou as espigas mais compridas, diferindo dos demais. Pelos resultados, primeiramente $\mathrm{P}_{5}$ e num plano inferior $\mathrm{P}_{3}$, constituem fontes genéticas para um programa de melhoramento, quando o objetivo for o aumento do comprimento da espiga, pois foram eficientes em transmitir essa característica a suas progênies. Resultados seme- lhantes foram obtidos por Ferreira Filho (1996) avaliando cruzamentos entre a cultivar BH-1146 e CMH 79.959/2* CNO $79\left(\mathrm{P}_{3}\right)$.

Quando se considerou o caráter comprimento do internódio da raque, $\mathrm{P}_{3}$ e $\mathrm{P}_{5}$ apresentaram as maiores médias, não diferindo entre si, porém diferindo dos demais. $\mathrm{P}_{4}$ exibiu a menor média, diferindo dos demais. Observaram-se diferenças significativas quanto a esse caráter nas populações híbridas $F_{1}$ e $F_{2}$ e nos retrocruzamentos. Pelos resultados, $\mathrm{P}_{4}$ seria fon- 
te de espigas mais densas e $\mathrm{P}_{3}$ e $\mathrm{P}_{5}$, de espigas menos densas ou com maior comprimento do internódio da raque.

Em relação à produção de grãos, $\mathrm{P}_{1}$ e $\mathrm{P}_{2}$ foram os mais produtivos, não diferindo entre si, porém diferindo dos demais. $\mathrm{P}_{4}$ apresentou-se como menos produtivo, diferindo estatisticamente dos demais. Os híbridos $\mathrm{P}_{1} \times \mathrm{P}_{3}$ e $\mathrm{P}_{1} \times \mathrm{P}_{5}$, em geração $\mathrm{F}_{1}$ não diferiram entre si e do híbrido $\mathrm{P}_{1} \times \mathrm{P}_{2}$ quanto à produção de grãos, porém diferiram do híbrido $\mathrm{P}_{1} \mathrm{xP}_{4}$. Os híbridos $\mathrm{P}_{1} \mathrm{xP}_{2}$ e $\mathrm{P}_{1} \times \mathrm{P}_{3}$, em geração $\mathrm{F}_{2}$ mostraram-se mais produtivos, não diferindo entre si, porém diferindo dos demais híbridos avaliados. Considerando-se os retrocruzamentos para o $1^{\circ}$ genitor, o híbrido $\left(\mathrm{P}_{1} \times \mathrm{P}_{5}\right) \times \mathrm{P}_{1}$ somente diferiu do híbrido $\left(\mathrm{P}_{1} \mathrm{XP}_{4}\right) \mathrm{xP}_{1}$, que mostrou a menor produção de grãos. Entre os

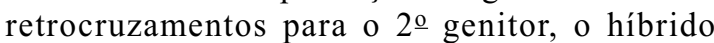
$\left(\mathrm{P}_{1} \mathrm{xP}_{2}\right) \mathrm{xP}_{2}$ somente não diferiu do híbrido $\left(\mathrm{P}_{1} \mathrm{xP}_{3}\right) \mathrm{xP}_{3}$ quanto a essa característica. Com exceção do $\mathrm{P}_{4}$, os demais genitores apresentaram potencial em transferir a suas progênies maior produção de grãos.

Os graus de dominância para altura da planta, comprimento da espiga e comprimento do internódio da raque na geração $F_{1}$ e $F_{2}$ encontram-se na Tabela 3. Os dados obtidos sugerem que os genes para porte baixo encontrados nos genótipos mexicanos $\left(\mathrm{P}_{2}, \mathrm{P}_{3}, \mathrm{P}_{4}\right.$ e $\left.\mathrm{P}_{5}\right)$ tiveram um comportamento parcialmente recessivo nas gerações $F_{1}$ e $F_{2}$ do cruzamento dessas fontes de nanismo com a cultivar IAC-227, de porte alto. $\mathrm{O}$ mesmo resultado foi obtido por Camargo \& Ramos (1989) nas gerações $F_{1}$ e $F_{2}$ de cruzamentos envolvendo a cultivar C-3 de porte alto com as linhagens Olesen, Vican-71 e Siete Cerros, de porte baixo.

Os graus de dominância para comprimento da espiga considerando os híbridos, em geração $\mathrm{F}_{1}$, entre o genitor $\mathrm{P}_{1}$, de espiga de comprimento intermediário com os parentais $\mathrm{P}_{2}, \mathrm{P}_{3}$, e $\mathrm{P}_{5}$, de espigas compridas, mostraram que os genes para espigas compridas encontradas nessas linhagens tiveram um comportamento parcialmente recessivo. Na geração $\mathrm{F}_{2}$, levando-se em conta os mesmos híbridos, verificou-se que, com exceção do $\mathrm{P}_{1} \mathrm{xP}_{2}$, os genes para espigas compridas apresentaram um comportamento parcialmente dominante. Esses resultados indicam que as linhagens envolvidas nesses híbridos diferem por muitos genes para o carácter em estudo, concordando com Ausemus et al. (1967) que afirmou que o comprimento da espiga é influenciado por muitos genes, os quais são localizados em todos os cromossomas do trigo, com exceção do 1B, 5A e 6D. Para o híbrido em gerações $\mathrm{F}_{1}$ e $\mathrm{F}_{2}$, entre o genitor $\mathrm{P}_{1}$, de espiga de comprimento intermediário e o genitor $\mathrm{P}_{4}$, de espigas curtas, verificou-se que os genes para espigas intermediárias mostraram um comportamento parcialmente dominante. A consistência entre os graus de dominância nas gerações $\mathrm{F}_{1}$ e $\mathrm{F}_{2}$, desse cruzamento sugerem que os genitores $\mathrm{P}_{1}$ e $\mathrm{P}_{5}$ diferem entre si por poucos genes quanto a essa característica.

TABELA3. Grau de dominância em relação a altura da planta, comprimento da espiga e comprimento do internódio da raque, nas gerações $F_{1}$ e $F_{2}$ de cruzamentos entre a cultivar IAC-227 $\left(P_{1}\right)$ e quatro linhagens mexicanas: CMH 78.390/ CMH 77A.917//CMH 79.215 ( $\left.\mathrm{P}_{2}\right)$; CMH 79.959/2* CNO $79\left(\mathrm{P}_{3}\right)$; CMH 79.481/CMH 77A.917 $\left(\mathrm{P}_{4}\right)$ e CMH 80A.747 $\left(\mathrm{P}_{5}\right)^{1}$.

\begin{tabular}{|c|c|c|c|c|c|c|}
\hline \multirow[t]{2}{*}{ Cruzamento } & \multicolumn{2}{|c|}{$\begin{array}{c}\text { Altura } \\
\text { da planta }\end{array}$} & \multicolumn{2}{|c|}{$\begin{array}{c}\text { Comprimento } \\
\text { da espiga }\end{array}$} & \multicolumn{2}{|c|}{$\begin{array}{l}\text { Comprimento do } \\
\text { internódio da raque }\end{array}$} \\
\hline & $\mathrm{F}_{1}$ & $\mathrm{~F}_{2}$ & $\mathrm{~F}_{1}$ & $\mathrm{~F}_{2}$ & $\mathrm{~F}_{1}$ & $\mathrm{~F}_{2}$ \\
\hline $\mathrm{P}_{1} \times \mathrm{P}_{2}$ & 0,352 & 0,038 & $-0,375$ & $-0,042$ & $-0,651$ & 0,111 \\
\hline $\begin{array}{lll}P_{1} & x & P_{3}\end{array}$ & - & 0,713 & $-0,208$ & 0,132 & $-0,531$ & $-0,235$ \\
\hline$P_{1} \quad x \quad P_{4}$ & 0,365 & 0,283 & 0,500 & 0,667 & 0,377 & 0,623 \\
\hline $\mathrm{P}_{1} \times \mathrm{P}_{5}$ & 0,227 & 0,083 & $-0,333$ & 0,101 & $-0,478$ & $-0,107$ \\
\hline
\end{tabular}

${ }^{1}$ Grau de dominância igual a +1 significa dominância completa dos genes que condicionam porte alto, ou maior comprimento da espiga ou maior comprimento do internódio da raque e -1 significa dominância completa dos genes que condicionam porte baixo ou espigas curtas ou menor comprimento do internódio da raque. 
Os híbridos, em geração $\mathrm{F}_{1}$ e $\mathrm{F}_{2}$ entre o $\mathrm{P}_{1}$, de comprimento intermediário do internódio da raque $\mathrm{e}$ os genitores $\mathrm{P}_{3}$ e $\mathrm{P}_{5}$, de grande comprimento do internódio da raque mostraram que os genes para maior comprimento tiveram comportamento parcialmente recessivo. Por outro lado, os híbridos, em gerações $F_{1}$ e $F_{2}$, entre o $P_{1}$ de comprimento intermediário do internódio da raque com o $\mathrm{P}_{5}$, de pequeno comprimento, indicaram que os genes para maior comprimento tiveram um comportamento parcialmente dominante. Pela consistência dos graus de dominância para as gerações $\mathrm{F}_{1}$ e $\mathrm{F}_{2}$, pode-se considerar que poucos genes estão envolvidos na herança dessa característica, o que está de acordo com os resultados citados por Ausemus et al. (1967). Considerando-se o híbrido entre os genitores $\mathrm{P}_{1} \times \mathrm{P}_{2}$, ambos com comprimento intermediário do internódio da raque, não diferindo entre si, verificou-se, em geração $F_{1}$ e $F_{2}$, graus de dominância negativo e positivo, respectivamente para maior comprimento do internódio da raque. Tais resultados sugerem que esses genótipos, apesar de não diferirem entre si, apresentam diferentes genes controlando essa característica.

Os valores da heterose calculados para a altura da planta (Tabela 4) nas gerações $F_{1}$ e $F_{2}$ dos cruzamentos entre IAC-227 e as quatro linhagens mexicanas, mostraram valores positivos, indicando que a altura da planta nesses cruzamentos foram superiores à média da altura dos genitores utilizados, confirmando os resultados obtidos para os graus de dominância, isto é, a dominância parcial dos genes que condicionam plantas mais altas. Não houve heterobeltiose nas gerações $F_{1}$ (com exceção do

TABELA 4. Heterose e heterobeltiose em relação a altura da planta, comprimento da espiga, comprimento do internódio da raque e produção de grãos nas gerações $F_{1}$ e $F_{2}$ de cruzamentos entre a cultivar IAC-227 $\left(P_{1}\right)$ e quatro linhagens mexicanas: $\mathrm{CMH}$ 78.390/CMH 77A.917//CMH 79.215 $\left(\mathrm{P}_{2}\right)$; CMH 79.959/2* CNO $79\left(\mathrm{P}_{3}\right)$; CMH 79.481/CMH 77A.917 $\left(\mathrm{P}_{4}\right)$ e CMH 80A.747 $\left(\mathrm{P}_{5}\right)$.

\begin{tabular}{|c|c|c|c|c|}
\hline \multirow[t]{2}{*}{ Cruzamento } & \multicolumn{2}{|c|}{ Heterose $^{1}$} & \multicolumn{2}{|c|}{ Heterobeltiose $^{2}$} \\
\hline & $\mathrm{F}_{1}$ & $\mathrm{~F}_{2}$ & $\mathrm{~F}_{1}$ & $\mathrm{~F}_{2}$ \\
\hline & \multicolumn{4}{|c|}{ Altura da planta } \\
\hline $\begin{array}{lll}\mathrm{P}_{1} & \mathrm{x} & \mathrm{P}_{2} \\
\mathrm{P}_{1} & \mathrm{x} & \mathrm{P}_{3} \\
\mathrm{P}_{1} & \mathrm{x} & \mathrm{P}_{4} \\
\mathrm{P}_{1} & \mathrm{x} & \mathrm{P}_{5}\end{array}$ & $\begin{array}{r}7,06 \\
15,97 \\
10,91 \\
6,66 \\
\end{array}$ & $\begin{array}{l}0,76 \\
7,81 \\
8,46 \\
2,45 \\
\end{array}$ & $\begin{array}{r}-10,82 \\
4,52 \\
-14,60 \\
-17,54 \\
\end{array}$ & $\begin{array}{r}-17,07 \\
-2,84 \\
-16,49 \\
-20,80 \\
\end{array}$ \\
\hline $\mathrm{P}_{1} \times \mathrm{P}_{5}$ & \multicolumn{4}{|c|}{ Comprimento da espiga } \\
\hline $\begin{array}{lll}\mathrm{P}_{1} & \mathrm{x} & \mathrm{P}_{2} \\
\mathrm{P}_{1} & \mathrm{x} & \mathrm{P}_{3} \\
\mathrm{P}_{1} & \mathrm{x} & \mathrm{P}_{4} \\
\mathrm{P}_{1} & \mathrm{x} & \mathrm{P}_{5}\end{array}$ & $\begin{array}{r}-8,91 \\
-5,31 \\
9,23 \\
-10,31 \\
\end{array}$ & $\begin{array}{r}-0,99 \\
3,88 \\
12,31 \\
3,14 \\
\end{array}$ & $\begin{array}{r}-26,40 \\
-24,61 \\
-7,79 \\
-31,51 \\
\end{array}$ & $\begin{array}{r}-20,00 \\
-17,69 \\
-5,19 \\
-21,23 \\
\end{array}$ \\
\hline$P_{1} \times P_{5}$ & \multicolumn{4}{|c|}{ Comprimento do internódio da raque } \\
\hline $\begin{array}{lll}\mathrm{P}_{1} & \mathrm{x} & \mathrm{P}_{2} \\
\mathrm{P}_{1} & \mathrm{x} & \mathrm{P}_{3} \\
\mathrm{P}_{1} & \mathrm{x} & \mathrm{P}_{4} \\
\mathrm{P}_{1} & \mathrm{x} & \mathrm{P}_{5}\end{array}$ & $\begin{array}{r}-4,43 \\
-12,91 \\
7,18 \\
-12,06 \\
\end{array}$ & $\begin{array}{r}0,76 \\
-5,71 \\
11,88 \\
-2,69 \\
\end{array}$ & $\begin{array}{r}-10,53 \\
-29,94 \\
-9,97 \\
-29,78 \\
\end{array}$ & $\begin{array}{r}-5,67 \\
-24,15 \\
-6,03 \\
-22,30 \\
\end{array}$ \\
\hline $\mathrm{P}_{1} \quad \mathrm{x} \mathrm{P}_{5}$ & \multicolumn{4}{|c|}{ Produção de grãos } \\
\hline $\begin{array}{llll}\mathrm{P}_{1} & \times & \mathrm{P}_{2} \\
\mathrm{P}_{1} & \mathrm{x} & \mathrm{P}_{3} \\
\mathrm{P}_{1} & \mathrm{x} & \mathrm{P}_{4} \\
\mathrm{P}_{1} & \mathrm{x} & \mathrm{P}_{5}\end{array}$ & $\begin{array}{r}6,50 \\
79,04 \\
18,38 \\
53,37\end{array}$ & $\begin{array}{l}11,89 \\
37,59 \\
16,13 \\
22,23\end{array}$ & $\begin{array}{r}2,91 \\
31,22 \\
-20,40 \\
14,85\end{array}$ & $\begin{array}{r}8,13 \\
0,84 \\
-21,92 \\
-8,46\end{array}$ \\
\hline
\end{tabular}

${ }^{1}$ Calculada como a porcentagem de aumento do $\mathrm{F}_{1}$ ou $\mathrm{F}_{2}$ sobre a média dos genitores.

${ }^{2}$ Calculada como a porcentagem de aumento do $\mathrm{F}_{1}$ ou $\mathrm{F}_{2}$ sobre a média do melhor genitor. 
$\mathrm{P}_{1} \mathrm{XP}_{3}$ ) e $\mathrm{F}_{2}$, mostrando que as médias dos híbridos foram inferiores à média da altura do genitor mais alto (IAC-227).

Para o caráter comprimento da espiga detectaramse valores negativos para a heterose dos cruzamentos $\mathrm{P}_{1} \mathrm{xP}_{2}$, nas gerações $\mathrm{F}_{1}$ e $\mathrm{F}_{2}, \mathrm{P}_{1} \mathrm{xP}_{3}$ e $\mathrm{P}_{1} \mathrm{xP}_{5}$, na geração $\mathrm{F}_{1}$, sugerindo que o comprimento da espiga nesses cruzamentos foram inferiores à média do comprimento da espiga dos genitores utilizados. Valores positivos foram observados nos cruzamentos $\mathrm{P}_{1} \mathrm{xP}_{4}$, nas gerações $\mathrm{F}_{1}$ e $\mathrm{F}_{2}, \mathrm{P}_{1} \times \mathrm{P}_{3}$, e $\mathrm{P}_{1} \mathrm{xP}_{5}$, na geração $\mathrm{F}_{2}$. Esses resultados estão de acordo com os verificados para os respectivos graus de dominância, isto é, valores negativos para a heterose estão relacionados com a dominância parcial dos genes que condicionaram espigas mais curtas, e valores positivos com a dominância parcial dos genes que condicionaram espigas mais longas. Todos os híbridos nas gerações $F_{1}$ e $F_{2}$ apresentaram menor comprimento da espiga em relação à média do genitor superior para esse caráter, mostrando, portanto, a não-existência de heterobeltiose.

Os valores da heterose calculados para o comprimento do internódio da raque foram negativos para os híbridos $\mathrm{P}_{1} \times \mathrm{P}_{2}$ (somente na geração $\mathrm{F}_{1}$ ), $\mathrm{P}_{1} \times \mathrm{P}_{3} \mathrm{e}$ $\mathrm{P}_{1} \mathrm{xP}_{5}$, nas gerações $\mathrm{F}_{1}$ e $\mathrm{F}_{2}$, e positivo para os híbridos $\mathrm{P}_{1} \times \mathrm{P}_{3}$, na geração $\mathrm{F}_{2}$, e $\mathrm{P}_{1} \times \mathrm{P}_{4}$, nas gerações $F_{1}$ e $F_{2}$, confirmando as estimativas dos graus de dominância, já apresentados, que mostraram no caso da heterose negativa a dominância parcial dos genes que condicionam espigas com menor comprimento do internódio da raque, e no caso da heterose positiva a dominância parcial dos genes que condicionam maior comprimento do internódio da raque. Nas gerações $F_{1}$ e $F_{2}$ dos híbridos estudados, sempre o comprimento do internódio da raque foi menor em relação ao genitor superior para esse caráter, mostrando, portanto, a não ocorrência de heterobeltiose.

Os valores da heterose calculados para produção de grãos foram positivos para todos os cruzamentos, nas gerações $F_{1}$ e $F_{2}$. Considerando-se que os híbridos $\mathrm{P}_{1} \times \mathrm{P}_{3}$ e $\mathrm{P}_{1} \times \mathrm{P}_{2}$ também mostraram valores positivos para heterobeltiose, nas gerações $F_{1}$ e $F_{2}$ verificou-se que esses híbridos que têm maior capacidade específica de combinação.

As estimativas da herdabilidade em sentido restrito, para os quatro caracteres estudados, derivados de dados obtidos na geração $F_{2} \mathrm{~s}$ e retrocruzamentos das quatro populações híbridas, encontram-se na Tabela 5.

Os valores da herdabilidade em sentido restrito para altura da planta, comprimento da espiga e comprimento do internódio da raque, foram médios a altos, para os quatro híbridos avaliados. Esses resultados indicam que grande parte da variabilidade genética total para essas características deve-se a genes que se comportam de maneira aditiva, corroborando os resultados de Kronstad \& Foote (1964), Johnson et al. (1966), Camargo et al. (1992) e Ferreira Filho (1996).

Foram obtidos valores médios da herdabilidade em sentido restrito para produção de grãos, em todos os cruzamentos, variando de 0,421 a 0,550 . Valores semelhantes foram também estimados por Ferreira Filho (1996).

Os valores altos estimados para a herdabilidade em sentido restrito para a altura da planta, em todos

TABELA 5. Estimativas da herdabilidade em sentido restrito ${ }^{1} \mathrm{em}$ relação a altura da planta, comprimento da espiga, comprimento do internódio da raque e produção de grãos, derivadas de dados obtidos em cruzamentos e retrocruzamentos entre a cultivar IAC-227 $\left(P_{1}\right)$ e quatro linhagens mexicanas: CMH 78.390/ CMH 77A.917//CMH 79.215 $\left(\mathrm{P}_{2}\right)$; CMH 79.959/2* CNO $79\left(\mathrm{P}_{3}\right)$; CMH 79.481/CMH 77A.917 $\left(\mathrm{P}_{4}\right)$ e CMH 80A.747 $\left(\mathrm{P}_{5}\right)$.

\begin{tabular}{lcccc}
\hline Caráter & $\mathrm{P}_{1} \times \mathrm{P}_{2}$ & $\mathrm{P}_{1} \times \mathrm{P}_{3}$ & $\mathrm{P}_{1} \times \mathrm{P}_{4}$ & $\mathrm{P}_{1} \times \mathrm{P}_{5}$ \\
\hline Altura da planta $(\mathrm{cm})$ & $0,608 \pm 0,038$ & $0,861 \pm 0,024$ & $0,755 \pm 0,041$ & $0,817 \pm 0,021$ \\
Comprimento da espiga $(\mathrm{cm})$ & $0,667 \pm 0,036$ & $0,639 \pm 0,036$ & $0,406 \pm 0,070$ & $0,557 \pm 0,042$ \\
Comprimento do internódio da raque $(\mathrm{cm})$ & $0,545 \pm 0,041$ & $0,596 \pm 0,037$ & $0,781 \pm 0,044$ & $0,556 \pm 0,040$ \\
Produção de grãos $(\mathrm{g})$ & $0,528 \pm 0,045$ & $0,421 \pm 0,046$ & $0,509 \pm 0,061$ & $0,550 \pm 0,032$ \\
\hline
\end{tabular}

1 Pelo método proposto por Warner (1952). 
os cruzamentos $(0,608$ a 0,861$)$, para comprimento da espiga nos cruzamentos $\mathrm{P}_{1} \mathrm{xP}_{2}(0,667)$ e $\mathrm{P}_{1} \mathrm{xP}_{3}(0,639)$, e para comprimento do internódio da raque no cruzamento $\mathrm{P}_{1} \mathrm{xP}_{4}(0,781)$ sugerem que a seleção para esses caracteres deveria ser efetiva nas primeiras gerações segregantes. Valores mais baixos da herdabilidade em sentido restrito foram estimados para comprimento da espiga nos cruzamentos $\mathrm{P}_{1} \mathrm{xP}_{4}$ $(0,406)$ e $\mathrm{P}_{1} \mathrm{xP}_{5}(0,557)$, para comprimento do internódio da raque nos cruzamentos $\mathrm{P}_{1} \times \mathrm{P}_{2}(0,545)$, $\mathrm{P}_{1} \mathrm{xP}_{3}(0,596)$ e $\mathrm{P}_{1} \times \mathrm{P}_{5}(0,556)$, e para produção de grãos nos quatro cruzamentos. A seleção para esses caracteres deveria ser realizada nas gerações mais avançadas quando o valor genético da progênie poderia ser mais precisamente determinado.

$\mathrm{Na}$ Tabela 6, encontram-se as correlações ambientes $\left(\mathrm{r}_{\mathrm{A}}\right)$, fenotípicas $\left(\mathrm{r}_{\mathrm{F}}\right)$ e genéticas $\left(\mathrm{r}_{\mathrm{G}}\right)$ entre produção de grãos, altura da planta, comprimento da

TABELA 6. Correlações ambientes $\left(r_{A}\right)$, fenotípicas $\left(r_{F}\right)$ e genéticas $\left(r_{G}\right)$ entre altura da planta, comprimento da espiga, comprimento do internódio da raque e produção de grãos para cada cruzamento envolvendo a cultivar IAC-227 $\left(\mathrm{P}_{1}\right)$ e quatro linhagens mexicanas: CMH 78.390/CMH 77A.917// CMH 79.215 (P $)$; CMH 79.959/2* CNO $79\left(\mathrm{P}_{3}\right)$; CMH 79.481/ CMH 77A.917 $\left(\mathrm{P}_{4}\right)$ e CMH 80A. $747\left(\mathbf{P}_{5}\right)$.

\begin{tabular}{|c|c|c|c|}
\hline $\begin{array}{l}\text { Cruzamento entre } \\
\text { genótipos }\end{array}$ & $\mathrm{r}_{\mathrm{A}}$ & $\mathrm{r}_{\mathrm{F}}$ & $\mathrm{r}_{\mathrm{G}}$ \\
\hline & \multicolumn{3}{|c|}{ Produção de grãos $\mathrm{x}$ altura da planta } \\
\hline $\mathrm{P}_{1} \times \mathrm{P}_{2}$ & $0,559 * *$ & $0,578^{* *}$ & 0,596 \\
\hline $\mathrm{P}_{1} \times \mathrm{P}_{3}$ & 0,106 & $0,443^{* *}$ & 0,685 \\
\hline $\mathrm{P}_{1} \times \mathrm{P}_{4}$ & $0,511 * *$ & $0,411 * *$ & 0,377 \\
\hline \multirow[t]{2}{*}{$\mathrm{P}_{1} \times \mathrm{P}_{5}$} & 0,261 & $0,418^{* *}$ & 0,511 \\
\hline & \multicolumn{3}{|c|}{ Produção de grãos $\mathrm{x}$ comprimento da espiga } \\
\hline $\mathrm{P}_{1} \times \mathrm{P}_{2}$ & $0,434 * *$ & 0,099 & $-0,123$ \\
\hline $\mathrm{P}_{1} \times \mathrm{P}_{3}$ & $0,346^{*}$ & 0,019 & $-0,269$ \\
\hline $\mathrm{P}_{1} \times \mathrm{P}_{4}$ & $-0,410 * *$ & $0,555^{* *}$ & $>1,000$ \\
\hline \multirow[t]{2}{*}{$\mathrm{P}_{1} \times \mathrm{P}_{5}$} & $0,599 * *$ & 0,077 & $-0,343$ \\
\hline & \multicolumn{3}{|c|}{ Produção de grãos $\mathrm{x}$ comprimento do internódio da raque } \\
\hline $\mathrm{P}_{1} \times \mathrm{P}_{2}$ & $0,324 * *$ & $-0,191 * *$ & $-0,636$ \\
\hline $\mathrm{P}_{1} \times \mathrm{P}_{3}$ & 0,110 & $-0,454 * *$ & $<-1,000$ \\
\hline $\mathrm{P}_{1} \times \mathrm{P}_{4}$ & $-0,074$ & $0,283 * *$ & 0,488 \\
\hline \multirow[t]{2}{*}{$P_{1} \times P_{5}$} & $0,526^{* *}$ & $-0,202 * *$ & $-0,791$ \\
\hline & \multicolumn{3}{|c|}{ Altura da planta $\mathrm{x}$ comprimento da espiga } \\
\hline $\mathrm{P}_{1} \times \mathrm{P}_{2}$ & $0,570 * *$ & 0,046 & $-0,250$ \\
\hline $\mathrm{P}_{1} \times \mathrm{P}_{3}$ & $0,392 * *$ & 0,053 & $-0,048$ \\
\hline $\mathrm{P}_{1} \times \mathrm{P}_{4}$ & $-0,265$ & $0,546^{* *}$ & $>1,000$ \\
\hline \multirow[t]{2}{*}{$P_{1} \times P_{5}$} & $0,354 *$ & 0,025 & $-0,112$ \\
\hline & \multicolumn{3}{|c|}{ Altura da planta $\mathrm{x}$ comprimento do internódio da raque } \\
\hline $\mathrm{P}_{1} \times \mathrm{P}_{2}$ & $0,391 * *$ & $-0,060$ & $-0,392$ \\
\hline $\mathrm{P}_{1} \quad \mathrm{X} \quad \mathrm{P}_{3}$ & 0,112 & $-0,304 * *$ & $-0,461$ \\
\hline $\mathrm{P}_{1} \times \mathrm{P}_{4}$ & 0,033 & $0,422 * *$ & 0,540 \\
\hline \multirow[t]{2}{*}{$\mathrm{P}_{1} \times \mathrm{P}_{5}$} & $0,296^{*}$ & $-0,048$ & $-0,197$ \\
\hline & \multicolumn{3}{|c|}{ Comprimento da espiga $\mathrm{x}$ comprimento do internódio da raque } \\
\hline $\mathrm{P}_{1} \times \mathrm{P}_{2}$ & $0,653^{* *}$ & $0,611^{* *}$ & 0,592 \\
\hline $\mathrm{P}_{1} \times \mathrm{P}_{3}$ & $0,372 *$ & $0,381 * *$ & 0,387 \\
\hline $\mathrm{P}_{1} \times \mathrm{P}_{4}$ & $0,460 * *$ & $0,709 * *$ & 0,965 \\
\hline $\mathrm{P}_{1} \times \mathrm{P}_{5}$ & $0,723 * *$ & $0,646^{* *}$ & 0,585 \\
\hline
\end{tabular}


espiga e comprimento do internódio da raque, para cada cruzamento envolvendo a cultivar IAC-227 e quatro linhagens mexicanas.

As correlações genotípicas e de ambientes foram, em diversos casos, muito diferentes em magnitude, e algumas vezes diferente mesmo em sinal. Resultados semelhantes foram relatados por Falconer (1960), que ainda postulou que uma diferença em sinal entre essas duas correlações mostra que as causas de variação genética e de ambiente afetam os caracteres por meio de diferentes mecanismos fisiológicos.

As correlações genotípicas calculadas entre a produção de grãos e a altura da planta, o comprimento da espiga e o comprimento do internódio da raque, entre a altura de planta e o comprimento da espiga e o comprimento do internódio da raque e entre o comprimento da espiga e o comprimento do internódio da raque, concordaram, em geral, com as obtidas para as correlações fenotípicas para os quatro cruzamentos.

As correlações fenotípicas entre produção de grãos e altura das plantas foram positivas e altamente significativas em todos os cruzamentos. Esses dados demonstraram a tendência de as plantas mais altas serem as mais produtivas, confirmando resultados de Camargo \& Ramos (1989).

As plantas com espigas mais compridas tenderam a ser mais produtivas no cruzamento $\mathrm{P}_{1} \mathrm{XP}_{4}$, concordando com os resultados obtidos por Camargo \& Oliveira (1983). Não ocorreram correlações fenotípicas entre o comprimento da espiga e produção de grãos nos demais cruzamentos estudados.

Considerando os cruzamentos $\mathrm{P}_{1} \times \mathrm{P}_{2}, \mathrm{P}_{1} \times \mathrm{P}_{3} \mathrm{e}$ $\mathrm{P}_{1} \mathrm{XP}_{5}$, verificou-se que as plantas mais produtivas eram as que apresentaram os menores comprimentos do internódio da raque (espigas densas). Porém no híbrido $\mathrm{P}_{1} \mathrm{xP}_{4}$, as plantas que mostraram maior comprimento do internódio da raque foram as que tiveram maior produção de grãos.

As plantas mais altas tenderam a apresentar as espigas mais compridas no cruzamento $\mathrm{P}_{1} \mathrm{xP}_{4}$. Não foram observadas associações entre altura da planta e comprimento da espiga nos demais cruzamentos estudados.

Nos cruzamentos $\mathrm{P}_{1} \mathrm{xP}_{3}$ e $\mathrm{P}_{1} \times \mathrm{P}_{4}$, as plantas mais altas foram associadas respectivamente com meno- res e maiores comprimentos do internódio da raque, não havendo associação entre essas características nos cruzamentos $\mathrm{P}_{1} \mathrm{xP}_{2}$ e $\mathrm{P}_{1} \mathrm{xP}_{5}$, considerando-se as correlações fenotípicas.

Considerando as associações positivas entre produção de grãos com plantas altas em todos os cruzamentos e as demais associações estimadas entre os caracteres, deveriam ser utilizadas grandes populações $F_{2}$ e $F_{3}$ para serem obtidos os recombinantes desejados de elevado potencial produtivo com porte semi-anão e apresentando espigas compridas e densas.

\section{CONCLUSÕES}

1. A cultivar IAC-227 $\left(\mathrm{P}_{1}\right)$, de porte alto, mostra dominância parcial para porte alto, quando em cruzamentos com as quatro linhagens mexicanas, de porte baixo.

2. Não há heterobeltiose para comprimento da espiga e comprimento do internódio da raque, em todos os cruzamentos, nas gerações $\mathrm{F}_{1}$ e $\mathrm{F}_{2}$; em relação à altura da planta verifica-se heterobeltiose somente no híbrido $\mathrm{P}_{1} \times \mathrm{P}_{3}$, em geração $\mathrm{F}_{1}$; não há heterobeltiose para produção de grãos nas gerações $\mathrm{F}_{1}$ e $\mathrm{F}_{2}$, do cruzamento $\mathrm{P}_{1} \times \mathrm{P}_{4}$ e na geração $\mathrm{F}_{2}$, do cruzamento $\mathrm{P}_{1} \mathrm{xP}_{5}$.

3. Seleções para as características altura da planta, comprimento da espiga nos cruzamentos $\mathrm{P}_{1} \times \mathrm{P}_{2}$ e $\mathrm{P}_{1} \times \mathrm{P}_{3}$, e comprimento do internódio da raque no cruzamento $\mathrm{P}_{1} \mathrm{xP}_{4}$ são efetivas nas gerações segregantes iniciais de cada cruzamento, em razão da grandeza dos valores estimados para a herdabilidade em sentido restrito.

4. Seleções para produção de grãos em todos os cruzamentos, para comprimento da espiga nos cruzamentos $\mathrm{P}_{1} \times \mathrm{P}_{4}$ e $\mathrm{P}_{1} \times \mathrm{P}_{5}$, e comprimento do internódio da raque nos cruzamentos $\mathrm{P}_{1} \mathrm{xP}_{2}, \mathrm{P}_{1 \times \mathrm{x}_{3}} \mathrm{e}$ $\mathrm{P}_{1} \mathrm{xP}_{5}$, devem ser feitas em gerações mais avançadas baseando-se em testes de progênies.

5. As correlações fenotípicas entre altura da planta com produção de grãos e entre comprimento da espiga e comprimento do internódio da raque são positivas e significativas em todos os cruzamentos, mostrando haver associação entre esses caracteres; portanto, o estudo de grandes populações $F_{2}$ é de interesse para assegurar maior freqüência de recombinantes desejáveis. 


\section{REFERÊNCIAS}

AUSEMUS, E.R.; McNEAL, F.H.; SCHIMIDT, J.W. Genetics and inheritance. In: QUISENBERRY, K.S.; REITZ, L.P. (Eds.). Wheat and wheat improvement. Madison : American Society of Agronomy, 1967. p.225-267.

CAMARGO, C.E. de O. Melhoramento do trigo. IX. Estudo genético de fontes de nanismo. Bragantia, Campinas, v.43, n.2, p.591-603, 1984.

CAMARGO, C.E. de O.; FELICIO, J.C.; FREITAS, J.G. de; BARROS, B. de C.; CASTRO, J.L. de. Melhoramento do trigo. XII. Novas linhagens a partir de cruzamentos para o Estado de São Paulo. Bragantia, Campinas, v.44, n.2, p.669-685, 1985.

CAMARGO, C.E. de O.; FERREIRA FILHO, A.W.P.; ROCHA, L.S. Melhoramento do trigo. XXVII. Estimativas de variância, herdabilidade e correlações em populações híbridas para produção de grãos, tolerância à toxicidade de alumínio e altura das plantas. Bragantia, Campinas, v.51, n.1, p.21-30, 1992.

CAMARGO, C.E. de O.; KRONSTAD, W.E.; METZGER, R.J. Parent-progeny regression estimates and associations of height levels with aluminum toxicity and grain yield in wheat. Crop Science, Madison, v.20, p.355-358, 1980.

CAMARGO, C.E. de O.; OLIVEIRA, O.F. de. Melhoramento do trigo. II. Estudo genético de fontes de nanismo para a cultura do trigo. Bragantia, Campinas, v.40, p.77-91, 1981.

CAMARGO, C.E. de O.; OLIVEIRA, O.F. de. Melhoramento do trigo. V. Estimativas da herdabilidade e correlações entre altura, produção de grãos e outros caracteres agronômicos em trigo. Bragantia, Campinas, v.42, p.131-148, 1983.

CAMARGO, C.E. de O.; RAMOS, V.J. Herdabilidades e associações entre número de grãos por espigueta, altura das plantas e produção de grãos em populações híbridas de trigo envolvendo diferentes fontes de nanismo. Pesquisa Agropecuária Brasileira, Brasília, v.24, n.12, p.1513-1521, 1989.

FALCONER, D.S. Introduction to quantitative genetics. New York : Ronald, 1960. 365p.

FERREIRA FILHO, A.W.P. Estimativa da herdabilidade e dos coeficientes de correlação, entre características agronômicas, em populações híbridas de trigo. Jaboticabal : Universidade Estadual Paulista-Faculdade de Ciências Agrárias e Veterinárias, 1996. 68p. Tese de Doutorado.

FONSECA, S.; PATTERSON, F.L. Yield components heritabilities and interrelationships in winter wheat (Triticum aestivum L.). Crop Science, Madison, v.8, p.614-617, 1968.

JOHNSON, V.A.; BIEVER, K.J.; HAUNOLD, A.; SCHMIDT, J.W. Inheritance of plant height, yield of grain, and other plant and seed characteristics in a cross of hard red winter wheat, Triticum aestivum L. Crop Science, Madison, v.6, p.336-338, 1966

KETATA, H.; EDWARDS, L.H.; SMITH, E.L. Inheritance of eight agronomic characters in a winter wheat cross. Crop Science, Madison, v.16, p.19-22, 1976.

KRONSTAD, W.E.; FOOTE, W.H. General and specific combining ability estimates in winter wheat (Triticum aestivum Vill., Host). Crop Science, Madison, v.4, p.616-619, 1964.

MATHER, K.; JINKS, J.L. Introduction to biometrical genetics. Ithaca : Cornell University Press, 1977. $213 \mathrm{p}$.

MATZINGER, D.F.; MANN, T.J.; COCKERHAN, C.C. Diallel crosses in Nicotiana tabacum. Crop Science, Madison, v.2, p.383-386, 1962.

WARNER, J.N. A method for estimating heritability. Agronomy Journal, Madison, v.44, p.427-430, 1952. 